\title{
SLEEP DISTURBANCE AND NOISE ANNOYANCE AND ENVIRONMENTAL NOISE EXPOSURE IN RESIDENTS OF TWO MAJOR SLOVAKIAN CITIES
}

\author{
L. ARGALASOVA ${ }^{1,{ }^{*}}$, T. KIMAKOVA $^{2}$, E. PANULINOVA ${ }^{3}$, A. FILOVA ${ }^{1}, A$. \\ PULTZNEROVA ${ }^{4}$, J. JURKOVICOVA
}

${ }^{1}$ Institute of Hygiene, Faculty of Medicine, Comenius University, Bratislava, Slovakia.

${ }^{2}$ Institute of Public Health and Hygiene, Faculty of Medicine, Pavol Jozef Safarik University, Kosice, Slovakia.

${ }^{3}$ Institute of Structural Engineering, Department of Geotechnics and Traffic Engineering, Faculty of Civil Engineering, Technical University of Kosice, Slovakia.

${ }^{4}$ Department of Railway Engineering, Faculty of Civil Engineering, University of Zilina, Zilina, Slovakia.

corresponding author: lubica.argalasova@fmed.uniba.sk

\begin{abstract}
The significant growth in traffic density in Slovakia, combined with the country's economic change, has resulted in new environmental noise issues, particularly in road traffic noise. The objective of this study was to assess and evaluate the impact of environmental noise on the psychosocial well-being of young healthy individuals in the two main Slovak cities of Bratislava and Kosice. To assess noise annoyance, interference with activities, and sleep disturbance, the ICBEN (The International Commission on the Biological Effects of Noise) anonymous validated "Noise annoyance questionnaire" was applied; noise levels were objectified by direct measurements using a sound level analyzer with a frequency analysis module. Young individuals between the ages of 20 and 30 were interviewed in Bratislava (533 respondents, 155 males) and Kosice (355 respondents, 111 males). The majority of the respondents in both cities were exposed to medium levels of road traffic noise $L_{A e q} \geq 60 \mathrm{~dB}$. In Bratislava, 27.82 $\%$ of respondents resided in the higher noise exposure category $L_{A e q}$ $\geq 70 \mathrm{~dB}$, while in Kosice, $39.9 \%$ resided in the lower noise exposure category $L_{A e q}<50 \mathrm{~dB}$. Road traffic noise annoys respondents in the higher noise exposure category in Bratislava $63.51 \%$, and even in the lower noise exposure category in Kosice, it interferes with reading and mental work, sleep and falling asleep $46.51 \%$. The study has identified traffic noise as an environmental issue in large cities, emphasizing the need for vulnerable individuals to be protected, particularly at night.
\end{abstract}

\section{Keywords:}

Road traffic noise;

Questionnaire;

Young adults;

Noise annoyance;

Sleep disturbance.

\section{Introduction}

The significant growth in traffic density in Slovakia, combined with the country's economic change, has resulted in new environmental noise issues, particularly in road traffic noise [1-3]. In recent decades, environmental (community) noise has received a lot of attention as a serious environmental health hazard [1, 2]. Road traffic noise is a widespread, inevitable, and ever-increasing environmental problem in large cities all over the world [4].

Around 56 million people (54\%) in the European Union live in places with more than 250000 people, and they are subjected to road traffic noise of more than the average $L_{D E N}$ (day-evening-night) $55 \mathrm{~dB}$ per year, which is regarded health-threatening [4, 5]. According to the WHO, at least 1 million healthy life years (disability-adjusted life-years) are lost each year due to environmental noise in highincome European States (population around 340 million people) [6]. 
In a population exposed to ambient noise, the most common social response is annoyance [7]. This is a psychological state that results from an unintended perception of influences or subordination to circumstances that cause an individual to have a negative attitude toward them because they intrude on his or her privacy, interfere with performing activities, or affect the quality of sleep.

Antipathy, irritation, and, in some circumstances, psychosomatic diseases are the consequences $[8,9]$.

Other non-auditory health outcomes that have been studied include cognitive impairment (mostly in children), sleep disturbance, and cardiovascular health impairment [4, 6, 8-10].

\section{Aim of the study}

The study aimed to determine the impact of environmental noise on the psychosocial well-being of young healthy individuals in the two largest Slovak cities Bratislava (437 726 inhabitants in 2020) and Kosice (238 593 inhabitants in 2020) [11] and to assess and compare noise annoyance as the most prevalent community response. This contribution determines the level of environmental noise annoyance and analyzes the results of a questionnaire survey among the respondents.

\section{Material and methods}

The ICBEN anonymous validated "Noise annoyance questionnaire" was used to assess noise annoyance, interference with activities and sleep disturbance [12]; noise levels were objectified by direct measurement using sound level analyzer with a module for frequency analysis.

\subsection{Exposure}

Equivalent sound levels $L_{\text {Aeq }}$ were assessed at selected locations in Bratislava and Kosice, shown in Fig. 1 and 3, according to the standard protocol in the morning 7:30 - 9:30 and in the evening 18:00 - 20:00, $[13,14]$. To assess the impact of traffic noise on annoyance and various activities, we classified the exposure to road traffic noise into three categories; equivalent noise levels $A$ up to $50 \mathrm{~dB}, 50-60 \mathrm{~dB}$ and $>60 \mathrm{~dB}$. We compared the data measured by us on individual streets with the bands publicly available in strategic noise maps for Bratislava and Kosice agglomerations, Fig. 2, 4, $[15,16]$

\subsection{Samples}

We compared two selected groups of young adults in the category from 20 to 30 years of age, who lived in the measured localities in Bratislava (533 respondents, 155 males) and Kosice (355 respondents, 111 males) for at least four years and signed an informed consent. They filled the anonymous validated "Noise annoyance questionnaire" $[12,17]$. The response rate was $85 \%$ in Kosice and $90 \%$ in Bratislava.

\subsection{The questionnaire, subjective response, psychosocial well-being and annoyance}

Both anonymous questionnaires in Bratislava and Kosice included demographic (age, gender, education, occupation) and behavioral questions (smoking, coffee and alcohol consumption) and questions on residence characteristics (building construction, type of residence, location, window orientation to quiet or noisy streets, ventilation, length of stay in an apartment). The questions on possible non-auditory health effects (noise annoyance from different sources, interference with various activities and sleep disturbance) were included as well. Respondents subjectively assessed their health status as well as the frequency of different medicaments use. We used a five-graded verbal rating noise annoyance scale (Not at all; Slightly; Moderately; Very; Extremely) which was recommended by experts from ICBEN [1, 12]. The given scale was for statistical purposes sometimes necessary to dichotomize (Not at all + Slightly; Moderately + Very + Extremely) or trichotomize (Not at all + Slightly; Moderately, Very + Extremely).

\subsection{Statistical analysis}

In biostatistical and epidemiological processing the methods of descriptive and analytical statistics were used. The relationships between continuous variables were assessed by two-tailed ttest and analysis of variance (ANOVA). To quantify the relations between categorical variables bivariate and stratified analyses were used (Pearson chi-square test, Mantel-Haenszel stratified 
analysis). The statistical packages SPSS, version 25 (International Business Machines Corp., New Orchard Road, Armonk, NY, USA) and Epilnfo ${ }^{\mathrm{TM}}, 2007$ (CDC, Atlanta, Georgia, USA) were applied for data analysis. The statistical significance level was set at $\alpha<0.05$.

\section{Results}

\subsection{Exposure}

The average sound intensity $A$ of measuring stations (20) in Kosice ranged from $39.00 \mathrm{~dB}$ to $70.6 \mathrm{~dB}$. To assess the impact of traffic noise on annoyance and interference with various activities, we have classified road traffic noise exposure into three categories; equivalent noise levels $A$ up to 50 $\mathrm{dB}, 50-60 \mathrm{~dB}$ and $>60 \mathrm{~dB}$. The classification was the same in Bratislava ( 80 sites), but equivalent noise levels ranged from $48.2 \mathrm{~dB}$ to $71.2 \mathrm{~dB}$, Fig. 1, 3. We compared the data measured by us on individual streets with the bands publicly available in strategic noise maps for Bratislava and Kosice agglomerations, Fig. 2, 4, [15, 16].

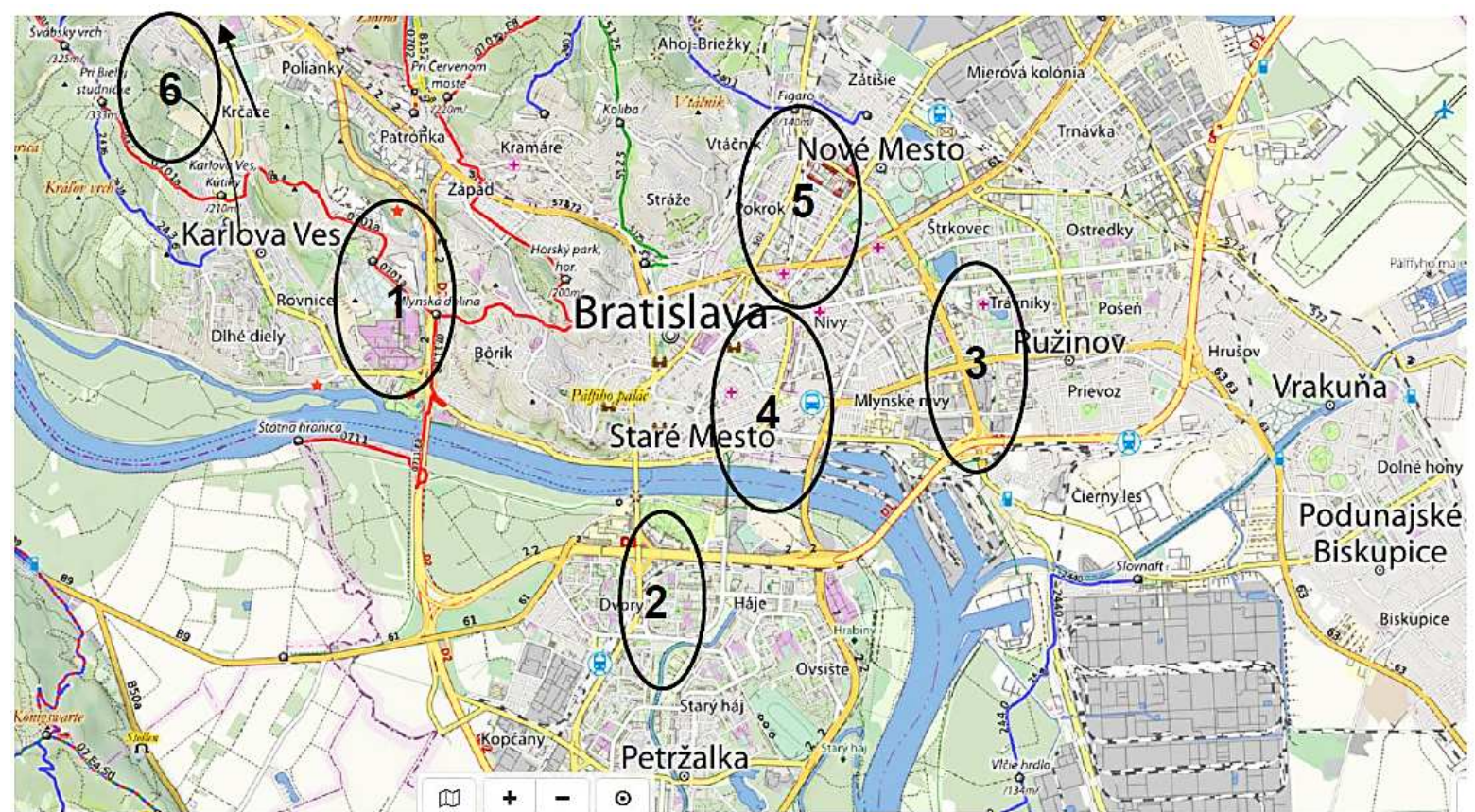

Fig. 1: Exposed respondents in Bratislava according to localities: 1 -Karlova Ves, 2 - Petrzalka, 3 - Ruzinov, 4 - Stare Mesto, 5 - Nove Mesto, 6 - Dubravka.

Table 1: Exposed respondents in Bratislava according to localities.

\begin{tabular}{|c|c|c|c|}
\hline \multirow{2}{*}{ Locality } & \multicolumn{3}{|c|}{ Categories of traffic noise exposure $L_{\text {Aeq }}[\mathrm{dB}]$} \\
\cline { 2 - 4 } & \multicolumn{3}{|c|}{ Number of respondents [n] } \\
\cline { 2 - 4 } & $<50 \mathrm{~dB}$ & $50-60 \mathrm{~dB}$ & $>60 \mathrm{~dB}$ \\
\hline Karlova Ves & 40 & 50 & 55 \\
\hline Petrzalka & 20 & 50 & 10 \\
\hline Ruzinov & 30 & 60 & 15 \\
\hline Stare Mesto & 15 & 45 & 10 \\
\hline Nove Mesto & 23 & 20 & 30 \\
\hline Dubravka & 20 & 29 & 10 \\
\hline Total & $148(24.44 \%)$ & $254(47.74 \%)$ & $130(27.82 \%)$ \\
\hline
\end{tabular}




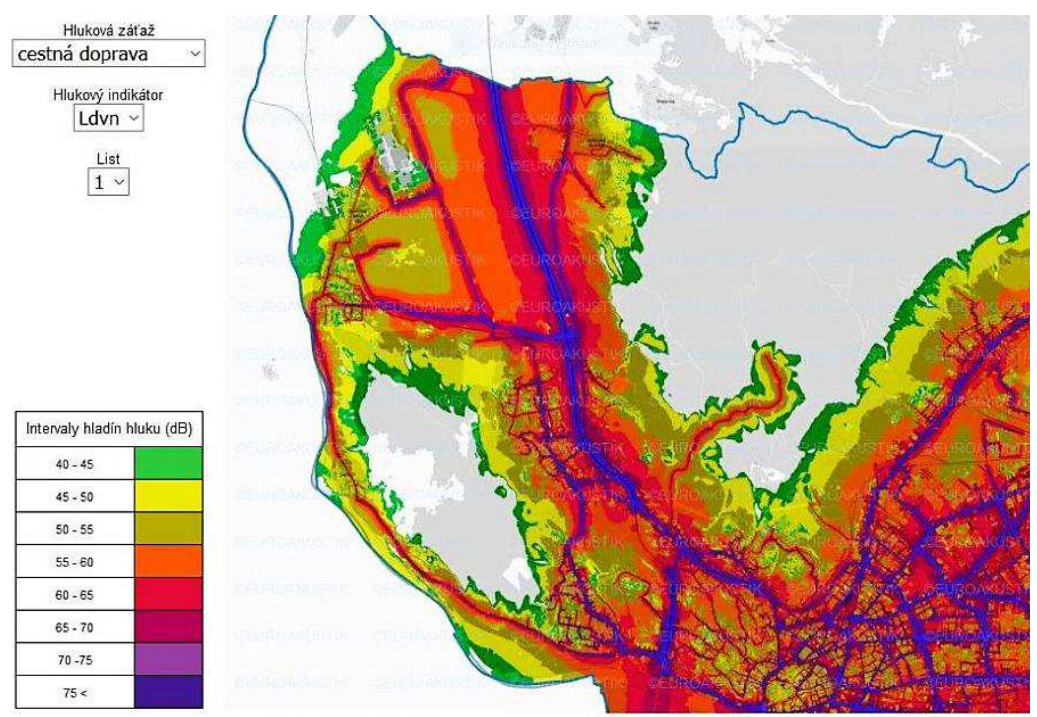

Fig. 2: Noise load in the Bratislava agglomeration according to the available strategic noise map from 2016 (source: EUROAKUSTIK, s.r.o.) [15].

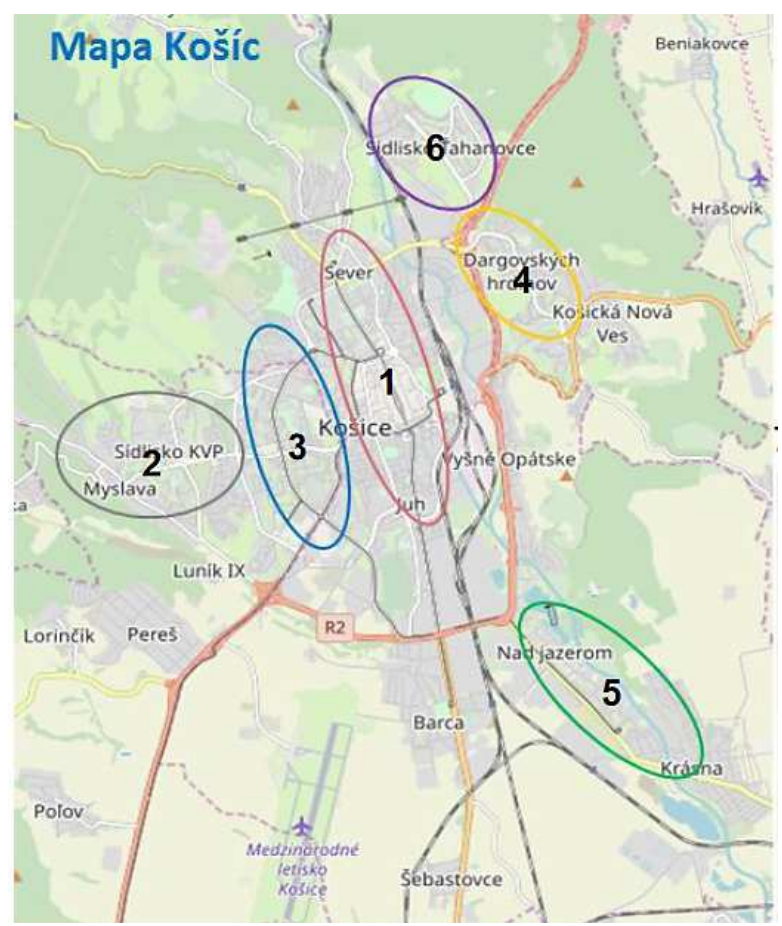

Fig. 3: Exposed respondents in Kosice according to localities: 1 - Centrum, $2-\mathrm{KVP}, 3-$ Terasa, 4 - Dargovskych hrdinov, 5 - Nad jazerom, 6 - Tahanovce.

Table 2: Exposed respondents in Kosice according to localities.

\begin{tabular}{|c|c|c|c|}
\hline \multirow{2}{*}{ Locality } & \multicolumn{3}{|c|}{ Categories of traffic noise exposure $L_{\text {Aeq }}[\mathrm{dB}]$} \\
\cline { 2 - 4 } & \multicolumn{3}{|c|}{ Number of respondents $[\mathbf{n}]$} \\
\cline { 2 - 4 } & $<50 \mathrm{~dB}$ & $50-60 \mathrm{~dB}$ & $>60 \mathrm{~dB}$ \\
\hline Centrum & 16 & 15 & 10 \\
\hline KVP & 19 & 11 & - \\
\hline Terasa & 10 & 6 & - \\
\hline Darg. hrdinov & 5 & 29 & - \\
\hline Nad jazerom & 11 & 15 & - \\
\hline Tahanovce & 20 & 26 & $20(9.85 \%)$ \\
\hline Total & $81(39.90 \%)$ & $102(50.25 \%)$ & \\
\hline
\end{tabular}




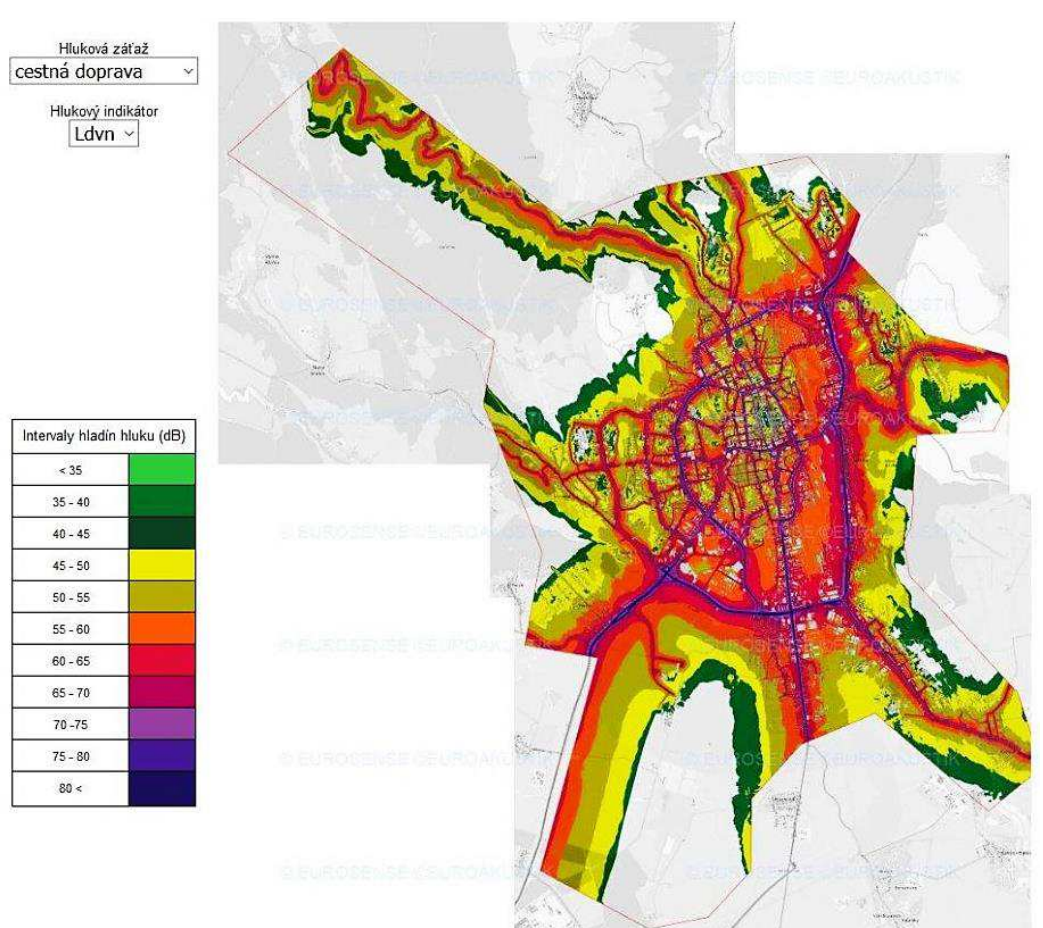

Fig. 4: Noise load in the Kosice agglomeration according to the available strategic noise map from 2011 (source: EUROAKUSTIK, s. r .o.) [16].

\subsection{The questionnaire, subjective response, psychosocial well-being and annoyance}

The results showed that in both cities most of the subjects were in the medium noise exposure category $L_{A e q}=50-60 \mathrm{~dB}$. In Bratislava there were $27.82 \%$ of respondents in the noise exposure category $L_{\text {Aeq }}>60 \mathrm{~dB}$ and in Kosice there were $39.90 \%$ of respondents in the noise exposure category $L_{\text {Aeq }}<50 \mathrm{~dB}$, Table 3 . Traffic noise annoys respondents especially in the noise exposure category $L_{A e q}>60 \mathrm{~dB}$ in Bratislava $63.51 \%$ and interferes with reading and mental work, sleep and falling asleep even in the noise exposure category $L_{\text {Aeq }}<50 \mathrm{~dB}$ in Kosice $46.91 \%$, Table 4.

Table 3: Proportions of respondents in individual noise exposure categories in Bratislava and Kosice.

\begin{tabular}{|c|c|c|c|c|}
\hline \multirow{2}{*}{ Categories of traffic noise exposure $\boldsymbol{L}_{\text {Aeq }}[\mathrm{dB}]$} & \multicolumn{2}{|c|}{ Respondents - Bratislava } & \multicolumn{2}{|c|}{ Respondents - Kosice } \\
\cline { 2 - 5 } & $\mathbf{N}$ & $\%$ & $\mathbf{N}$ & $\%$ \\
\hline$<50$ & 130 & 24.44 & 81 & 39.90 \\
\hline $50-60$ & 254 & 47.74 & 102 & 50.25 \\
\hline$>60$ & 148 & 27.82 & 20 & 9.85 \\
\hline Total & 532 & 100.00 & 203 & 100.00 \\
\hline
\end{tabular}

Table 4: Proportions of road traffic noise annoyance, sleep disturbance and interference with reading and mental work in different noise exposure categories in Bratislava and Kosice.

\begin{tabular}{|c|c|c|c|c|c|c|}
\hline \multirow{3}{*}{$\begin{array}{c}\text { Categories of traffic } \\
\text { noise exposure } L_{\text {Aeq }} \\
\text { [dB] }\end{array}$} & \multicolumn{3}{|c|}{ Bratislava } & \multicolumn{3}{|c|}{ Kosice } \\
\hline & $\begin{array}{l}\text { Noise } \\
\text { annoyance }\end{array}$ & $\begin{array}{l}\text { Sleep } \\
\text { disturbance }\end{array}$ & $\begin{array}{l}\text { Reading and } \\
\text { mental work }\end{array}$ & $\begin{array}{c}\text { Noise } \\
\text { annoyance }\end{array}$ & $\begin{array}{c}\text { Sleep † } \\
\text { disturbance }\end{array}$ & $\begin{array}{c}\text { Reading } \ddagger \text { and } \\
\text { mental work }\end{array}$ \\
\hline & $\%$ & $\%$ & $\%$ & $\%$ & $\%$ & $\%$ \\
\hline$<50$ & 16.92 & 26.92 & 28.46 & 18.51 & 46.91 & 32.10 \\
\hline $50-60$ & 28.85 & 32.94 & 33.20 & 35.29 & 59.81 & 25.49 \\
\hline$>60$ & 63.51 & 65.31 & 60.54 & 40.00 & 55.00 & 25.00 \\
\hline
\end{tabular}

$p$-value $<0.001, \dagger p$-value $=0.09, \ddagger p$-value $=0.553 ; p$-value is the probability of obtaining results at least as extreme as the observed results of a statistical hypothesis test, assuming that the null hypothesis is correct.

In Bratislava, road traffic noise interfered with respondents' reading and mental work mostly in the noise exposure category $L_{\text {Aeq }}>60 \mathrm{~dB}$. In Kosice, road traffic noise interfered with respondents' reading and mental work in all exposure categories, even in the category $L_{A e q}<50 \mathrm{~dB}$. Similarly, it was 
with sleep disturbance concerning noise exposure. In Kosice, the results among the noise exposure categories were not significant concerning sleep disturbance and reading and mental work interference, Table 4.

\section{Discussion}

In our study, we found out that in the selected groups of young and healthy individuals, in Bratislava $17.92 \%$ and in Kosice $16.90 \%$ of the sample reported serious sleep disturbance and sleep disorders in total without division into individual categories and the dominant source was road traffic noise.

The results are similar to those of the LARES study and the study from Skopje, Macedonia [18, 19]. The LARES study was conducted under the auspices of the WHO in 8 European countries and showed that $23 \%$ of the population had sleep disorders and the dominant source of noise was traffic noise (including road, rail and air traffic) as well as noise from neighboring flats [18]. In Skopje, $26 \%$ of respondents had sleep disorders and the dominant sources were neighborhood noise and road traffic noise [19]. In the present study, in Kosice $16.51 \%$ and in Bratislava $16.73 \%$ of young respondents annoyed neighbors.

In the recent cross-sectional study in Slovakia the authors focused on subjective traffic noise annoyance and sleep disturbance among the residents living close to major inner-city corridors in major Slovak towns. The subjective adaptation to traffic noise, subjective evaluation of health status and well-being were assessed as well. Traffic noise annoyed $48 \%$ of respondents during the day. In the exposed group living close to noisy traffic communications road traffic noise interfered with listening to radio and TV (73\% of respondents), with reading and mental work (51\%), with falling asleep (48\%) and sleep (42\%) in the exposed group living close to noisy traffic communications [20].

There are only a few studies on young healthy individuals and their traffic noise annoyance and sleep disturbance. Argalasova et al. identified the association between environmental noise and noise annoyance in the course of 25 years on different samples of medical students enrolled at Comenius University and living in Bratislava dormitories. The authors observed a sharp increase of road traffic noise annoyance and interference with various activities especially in the course of 10 years in 1989 and 1999. Interference with sleep and rest disturbance by road traffic noise has been increasing even after 25 years [3].

In the recent Slovak study on the sample of 1,003 university students living in college dormitories road traffic, neighborhood and entertainment facilities noise annoyance and sleep disturbance represented an important issue. Students in the dormitory exposed to road traffic noise reported more frequent listening to personal music players (PMPs) than students in the dormitory not exposed to road traffic noise [21].

The presented study compares noise annoyance, sleep disturbance as well as road traffic noise exposure in two major Slovak cities on a vulnerable group of young and healthy individuals. In the future we would like to enlarge the study sample and analyze data from different age categories as well as health conditions of respondents in both cities with a special emphasis on chronic diseases related to long term noise exposure, annoyance and sleep disturbance.

The presented study represents a significant contribution to the monitoring of noise exposure and its health effects in Bratislava and Kosice. The results can serve as a material in the processing of strategic noise maps and in proposals for effective organizational, technical and economic measures to reduce noise exposure in given localities.

\section{Conclusion}

This study has shown the extent of road traffic noise as the environmental problem in large cities and its effects on the exposed population; it emphasizes the need of protection of the possible vulnerable groups, especially during sleep. Furthermore, it would be of benefit if directions of this study are implemented in the new public health policy and other related policies (transport, space planning, urbanization) and strict application of noise management regulations.

\section{Acknowledgements}

This contribution is the result of the research partly supported by the grants VEGA G1/0006/2 and VEGA 1/0374/19. 


\section{References}

[1] SOBOTOVA, L. - JURKOVICOVA, J. - VOLEKOVA, J. - AGHOVA, L.: Community noise annoyance risk in two surveys. Int J Occup Med Environ Health,Vol. 14, Iss. 2, 2001, pp.197-200.

[2] ARGALASOVA - SOBOTOVA, L. - MIHALCIK, L. - JAJCAJ, M. - JURKOVICOVA, J. SEVCIKOVA, L.: Noise as a public health problem in Slovakia. In: Belojevič G. et al. (Eds.) Needs assessment of capacity building on health risk assessment of environmental noise: Case studies. WHO Regional Office for Europe. Copenhagen, 2012. https://www.euro.who.int/_data/ assets/pdf_file/0007/179116/Assessment-of-needs-for-capacity-building-for-health-risk-assessment -of-environmental-noise,-case-studies-ver-2.pdf (2021 - 08-29).

[3] ARGALASOVA, L. - JURKOVICOVA, J. - SEVCIKOVA, L. - STEFANIKOVA, Z. - HIROSOVA, K. BABJAKOVA, J. - KANOVICSOVA, A. - FILOVA, A.: Environmental noise and annoyance in the urban area at different time intervals. AMM, Vol. 617, 2014, pp. 110-115.

[4] Environmental Noise Guidelines for the European Region. WHO Regional Office for Europe. Copenhagen, 2018, https://www.euro.who.int/en/health-topics/environment-and-health/noise/enviro nmental-noise-guidelines-for-the-european-region (2021 - 08-29).

[5] HURTLEY, CH.: (Ed.) Night noise guidelines for Europe. Geneva: WHO 2009. 184 p. https://www. euro.who.int/_data/assets/pdf_file/0017/43316/E92845.pdf (2021 - 08-29).

[6] FRITSCHI, L. - BROWN, L.A. - KIM, R.- SCHWELA, D.- KEPHALOPOULOS, S.: Burden of disease from environmental noise. Quantific.ation of healthy life years lost in Europe. Geneva: World Health Organization, 2011. 106 p. http://www.who.int/quantifying_ehimpacts/publications/ e94888.pdf (2019-07-20) (2021 - 08-29).

[7] OUIS, D.: Annoyance from road traffic noise: a review. J. Environ. Psychol., Vol. 21, 2001, pp.101120.

[8] BASNER, M. - BRINK, M. - BRISTOW, A. - DE KLUIZENAAR, Y. - FINEGOLD, L. - HONG, J. et al.: ICBEN review of research on the biological effects of noise 2011-2014. Noise Health, Vol. 17, Iss. 75, 2015, pp. 57-82.

[9] YOUNES, M. - HEIKAL, A. - KOTB, A. - ZOHNY, H.: Assessment of Train Noise at Platforms in Underground Metro Stations. Civil and Environmental Engineering, Vol. 17, Iss.1, 2021, pp. 125138.

[10] BABISCH, W.: Updated exposure-response relationship between road traffic noise and coronary heart diseases: a meta-analysis. Noise Health, Vol. 16, Iss. 68, 2014, pp. 1-9.

[11] Statistical Office of Slovak Republic SR, 2021, http://statdat.statistics.sk (public database).

[12] FIELDS, J. M. - DE JONG, R. G. - GJESTLAND, T. - FLINDELL, I. H. - JOB, R. F. S. - KURRA, $S$. et al.: Standardized general-purpose noise reaction questions for community noise surveys: Research and recommendation. J. Sound Vib, Vol. 242, Iss.4, 2001, pp. 641-679.

[13] DECREE No. 549/2007 Coll. (Slovak Republic). Health Protection From Negative Impacts of Noise, Infrasound and Vibration and about requirements for objectification in living environment [in Slovak]; 2007.

[14] STN ISO 1996-2: 2019 (01 1621), Acoustics. Description, measurement and assessment of environmental noise. Part 2Determination of sound pressure levels [in Slovak]. Bratislava, Slovak Metrological Inspectorate, 2019, 56.

[15] EUROAKUSTIK, s.r.o. Strategic noise maps. Graphic presentation of the noise load of the Bratislava agglomeration for the situation in 2016. http://www.hlukovamapa.sk/graf_ba_2016.html (2021 - 08-29).

[16] EUROAKUSTIK, s.r.o. Strategic noise maps. Graphic presentation of the noise load of the Kosice agglomeration for the situation in 2011. http://www.hlukovamapa.sk/graf_ke_2011.html (2021 08-29.)

[17] KUZMOVA, L.: Dôsledky expozície hluku na zdravie obyvatel'ov Košíc (Consequences of noise exposure on the health of Kosice residents). PhD Thesis. Kosice: Institute of Public Health and Hygiene, Pavol Jozef Safarik University, Faculty of Medicine, 2018, 118.

[18] NIEMANN, H. - MASCHKE, C.: Noise effects and morbidity. WHO LARES Final report, EUR/04/5047477, WHO 2004, 20 p.

[19] RISTOVSKA, G. - GJORGJEV, D. - STIKOVA, E. - PERTOVA, V. - CAKAR M. D.: Noise Induced Sleep Disturbance in Adult Population: Cross-Sectional Study in Skopje Urban Centre. Open Access Maced J Med Sci.,Vol. 15, 2009, pp. 255-260.

[20] ARGALASOVA, L. - MIHALCIK, L. - VONDROVA, D. - FILOVA, A. - SIMONOVIC, J. JURKOVICOVA, J.: Does bedroom windows orientation contribute to annoyance and sleep disturbance? A questionnaire survey. In: The 13th ICBEN Congress on Noise as a Public Health Problem, Karolinska Institutet, Stockholm, Sweden, 14-17 June 2021 http://www.icben.org/2021/ index.html\#6 (2021 - 08-29). 
[21] FILOVA, A.. - JURKOVICOVA, J. - HIROSOVA, K. - VONDROVA, D. - FILOVA, B. - SAMOHYL, M. et al.: Social Noise Exposure in a Sample of Slovak University Students. Int. J. Environ. Res. Public Health, Vol. 17, 2020, 324. https://doi.org/10.3390/ijerph17010324 (2021 - 08-29). 